\title{
ANATOMIA DA MADEIRA DE ALBIZIA INUNDATA (MART.) BARNEBY \& J.W. GRIMES (FABACEAE) ${ }^{1}$
}

\author{
TALITA BALDIN² JOSÉ NEWTON CARDOSO MARCHIORI ${ }^{3}$
}

\section{RESUMO}

É descrita a estrutura anatômica da madeira de Albizia inundata (Mart.) Barneby \& J.W. Grimes, com base em material procedente do Rio Grande do Sul. Dos caracteres observados, salientam-se: porosidade difusa; vasos arredondados, predominantemente solitários; elementos vasculares curtos; placas de perfuração simples; parênquima paratraqueal abundante, compondo largas faixas alternas às fibras; raios homogêneos de até 11 células de largura; e fibras libriformes septadas.

Palavras-chave: Albizia inundata, Anatomia da Madeira, Fabaceae, Leguminosae, Mimosoideae.

\section{ABSTRACT}

[Wood anatomy of Albizia inundata (Mart.) Barneby \& J.W. Grimes (Fabaceae)].

The wood structure of Albizia inundata (Mart.) Barneby \& J.W Grimes is anatomically described based on material from Rio Grande do Sul State, Brazil. Among the observed features, the following stands out: diffuse porous wood; rounded vessels, mostly solitary; short vascular elements; simple perforation plates; abundant paratracheal parenchyma, forming wide bands alternating with fibers; homogeneous rays up to 11 cells wide; and libriform septate fibers.

Key words: Albizia inundata, Fabaceae, Leguminosae, Mimosoideae, Wood Anatomy.

\section{INTRODUÇÃO}

Conhecida pelos nomes populares de timbóbranco, bigueiro, biguazeiro, canafístula e muquém (Lorenzi, 1998), Albizia inundata (Mart.) Barneby \& J.W. Grimes apresenta ampla distribuição geográfica na América do Sul, ocorrendo, naturalmente, no Brasil, Paraguai, Argentina e Uruguai (Izaguirre \& Beyhaut, 2003).

De acordo com Lorenzi (1998), a espécie se encontra, naturalmente, na Região Amazônica, no vale do rio São Francisco e no Pantanal Matogrossense, em matas ciliares e várzeas inundáveis.

1 Recebido em 04-7-2014 e aceito para publicação em 21-7-2014

2 Engenheira Florestal. Mestranda do Programa de PósGraduação em Engenharia Florestal, Universidade Federal de Santa Maria. talita.baldin@ hotmail.com

3 Engenheiro Florestal, Professor Titular, Dr., Departamento de Ciências Florestais, Universidade Federal de Santa Maria. Bolsista de Produtividade em Pesquisa (CNPq-Brasil).marchiori@pq.cnpq.br
Para a província argentina de Entre Rios, Burkart (1987) indica sua ocorrência tanto em ilhas como à margem dos rios Paraná, Uruguai e principais afluentes, até o Delta Superior e Médio do rio da Prata.

Na República Oriental do Uruguai, a espécie foi assinalada para "zonas úmidas próximo à água”, em matas ciliares do rio Uruguai (Brussa \& Grela, 2007).

Embora "ainda não observada" em Santa Catarina, Burkart (1979), mesmo assim, aventa a possibilidade de sua ocorrência natural no sudoeste do estado ${ }^{4}$, nos municípios de Chapecó, Palmitos, Mondaí e Itapiranga. Sobre este ponto, Marchiori \& Alves (2012) opinaram ser altamente improvável sua ocorrência nessa região - e não apenas pela ausência de registros em herbário -, mas devido a questões geomorfológicas, pela ausência de planícies

\footnotetext{
4 BURKART (1979), em verdade, refere-se a Cathormium polyanthum (A. Spreng.) Burkart, binômio atualmente reduzido à sinonímia de Albizia inundata (Mart.) Barneby \& J.W. Grimes.
} 
sedimentares expressivas no extremo oeste catarinense.

No Rio Grande do Sul, a primeira referência à espécie ${ }^{5}$, feita por Marchiori (1997), foi contestada por Sobral et al. (2006) com base na ausência de registro em herbários. Para sanar definitivamente a dúvida, Marchiori \& Alves (2012) publicaram uma curta nota sobre a ocorrência natural da espécie no extremo sudoeste do estado, município de Barra do Quaraí, e encaminharam coletas de material fértil a diversos herbários da região.

Espécie ainda desconhecida na literatura anatômica brasileira, o presente artigo visa, precisamente, a sanar esta lacuna, bem como a analisar a estrutura do lenho sob o ponto de vista taxonômico e ecológico.

\section{REVISÃO DE LITERATURA}

Para a família Leguminosae (= Fabaceae), Record \& Hess (1943) relacionaram, entre outros caracteres anatômicos: porosidade difusa; vasos solitários ou em pequenos múltiplos; placas de perfuração exclusivamente simples; raios homogêneos; séries cristalíferas abundantes; parênquima paratraqueal abundante, frequentemente conspícuo; e fibras com pontoações simples, septadas em diversos gêneros.

Para o gênero Albizia, Metcalfe \& Chalk (1972) referem: vasos de diâmetro médio, com tendência a padrão oblíquo ou em séries tangenciais; porosidade semidifusa, em algumas espécies; pontoações intervasculares alternas, pequenas e ornamentadas; pontoações para com o parênquima, semelhantes às intervasculares; elementos vasculares de 0,2-0,4 $\mu \mathrm{m}$ de comprimento; parênquima paratraqueal abundante, com cristais em câmaras e, por vezes, terminal; raios com 4-7 células de largura, pelo menos em parte das espécies, e com frequiência de 4 a

Sob o binômio de Cathormion polyanthum (A. Spreng.) Burkart, a espécie foi incluída em obra dendrológica sobre as Leguminosas nativas do Rio Grande do Sul. Na segunda edição do livro (MARCHIORI, 2007), a espécie já foi descrita como Albizia inundata, binômio atualmente válido. 8/mm (até 14), raramente com cristais; e fibras septadas de pontoações simples, mais numerosas nas faces radiais, com paredes finas a muito espessas.

Das espécies brasileiras, Mattos et al. (2003) descreveram Albizia niopoides (Spruce ex Benth.) Burkart; Marchiori (1995), por sua vez, descreveu Albizia austrobrasilica Burkart, espécie incluída em "Madeiras do Rio Grande do Sul" sob o binômio de Albizia edwallii (Hoehne) Barneby \& J.W. Grimes (Marchiori et al., 2009).

Para Albizia niopoides foram referidos: anéis de crescimento distintos, em linhas onduladas tangenciais mais escuras; vasos de 58-95-154 $\mu \mathrm{m}$ de diâmetro, com frequiência de 6-10-16/ $\mathrm{mm}^{2}$; poros solitários e em múltiplos de 2 a 7 ; porosidade difusa; elementos vasculares de 134300-413 $\mu \mathrm{m}$ de comprimento; placas de perfuração simples, transversais; pontoações intervasculares alternas, ornamentadas; fibras septadas de 470-719-912 $\mu \mathrm{m}$ de comprimento, com pontoações simples e paredes medianas a espessas $(2-4-6 \mu \mathrm{m})$; parênquima paratraqueal em faixas, com séries de 2-4 células e cristais em câmaras; e raios em número de 6-8-10/mm, de 31-183-305 $\mu \mathrm{m}$ de altura, com 3-14-22 células, e 7-17-26 $\mu \mathrm{m}$ de largura (Mattos et al., 2003).

Para Albizia edwallii (sin.: A. austrobrasilica), foram referidos: anéis de crescimento distintos, individualizados por zonas fibrosas tangenciais mais escuras, parênquima marginal e concentração de poros no início do anel; vasos arredondados (37-64-93 $\mu \mathrm{m})$, em múltiplos radiais de 2 a 8 , solitários e em cachos; elementos vasculares de 155-243-348 $\mu \mathrm{m}$ de comprimento; placas de perfuração simples, oblíquas a transversais; pontoações intervasculares alternas; fibras de 735-1125-1362 $\mu$ m de comprimento, com paredes espessas; parênquima paratraqueal escasso, apotraqueal difuso e marginal; células parenquimáticas fusiformes e em séries de 2-4; e raios em número de 6-8,5-12/ $\mathrm{mm}$, de 22-76-240 $\mu \mathrm{m}$ de altura, com 1-3-9 células, e até 5-6 células de largura (Marchiori 1985; Marchiori et al., 2009). 
Cabe destacar que a espécie em estudo foi anatomicamente descrita para a Argentina, por Tortorelli (1956), sob o nome científico de Arthrosamanea polyantha (A. Spreng.) Burkart ${ }^{6}$, binômio atualmente reduzido à sinonímia de Albizia inundata (Mart.) Barneby \& J.W. Grimes. Na descrição microscópica da madeira, o autor relacionou, entre outros aspectos: anéis de crescimento pouco demarcados; poros arredondados (50-100-135 $\mu \mathrm{m})$, solitários e em múltiplos radiais de 2 a 3 , com frequência de 8 a $46 / \mathrm{mm}^{2}$; elementos vasculares curtos (até $200 \mu \mathrm{m}$ ); placas de perfuração simples; pontoações intervasculares alternas, pequenas, com abertura linear inclusa; raios em número de 4 a $7 / \mathrm{mm}$, predominantemente trisseriados e com até 40 células de altura; parênquima axial abundante, confluente em largas faixas interrompidas (de 7 a 30 células), mais largas do que as faixas de fibras; e fibras libriformes septadas, curtas $(950 \mu \mathrm{m})$, de paredes delgadas e com escassas pontoações simples.

\section{MATERIAL E MÉTODOS}

O material estudado consiste de uma amostra de madeira coletada do tronco de um indivíduo adulto, aparentemente saudável e à altura do peito. O material botânico correspondente foi depositado nos herbários SMDB, ICN, PACA, SI e HDCF, constando os seguintes registros:

- BRASIL: Rio Grande do Sul, Barra do Quaraí; à beira do rio Quaraí, cerca de 30m a leste da ponte; flores branco-esverdeadas; Marchiori \& Alves n. 1013, 03-12-2011.

Para a confecção de lâminas histológicas, foram extraídos três corpos-de-prova ( 1 x 2 × 3 $\mathrm{cm}$ ) da parte mais externa do lenho, próxima ao câmbio vascular, orientados para a obtenção de cortes anatômicos nos planos transversal, longitudinal radial e longitudinal tangencial. Ou-

6 TORTORELLI, L.A. Maderas y bosques argentinos. Buenos Aires: ACME, 1956. p. 359-361. tro bloquinho foi também retirado, com vistas à maceração.

No preparo de lâminas de cortes anatômicos, os corpos-de-prova foram amolecidos por fervura em água e seccionados em micrótomo de deslizamento, regulado para a obtenção de cortes com espessura nominal de $20 \mu \mathrm{m}$. Os cortes foram tingidos com safranina e azul de astra, desidratados em série alcoólica ascendente (30\%. 50\%, 75\%, 90\%, 95\%, duas vezes álcool absoluto), seguindo-se a passagem em xilol e montagem permanente, com "Entellan". Para as lâminas de macerado, usou-se o método de Jeffrey (Burger \& Richter, 1991), coloração da pasta com safranina $1 \%$ e montagem permanente, com a mesma resina anteriormente referida.

A descrição microscópica seguiu as normas do IAWA Committee (1989). Para as percentagens de tecidos, usou-se um contador de laboratório e 600 determinações ao acaso, de acordo com Marchiori (1980). O número de poros/ $\mathrm{mm}^{2}$ foi obtido de forma indireta, a partir de um quadrado de área conhecida superposto a fotomicrografias da seção transversal da madeira. As medições e determinações estereológicas foram realizadas no Laboratório de Anatomia da Madeira da Universidade Federal de Santa Maria, usando-se micrótomo fotônico binocular, com diferentes aumentos. Na descrição anatômica, os números entre parênteses correspondem aos valores mínimos e máximos observados; o valor que acompanha a média é o desvio padrão. Os valores quantitativos são resumidos na Tabela 1.

As fotomicrografias da Figura 1 foram tomadas em fotomicroscópio Leica DM 1000, no Laboratório de Anatomia da Madeira do CESNORS - UFSM.

\section{DESCRIÇÃO ANATÔMICA}

Anéis de crescimento: distintos, individualizados por fibras ligeiramente achatadas e poros de menor diâmetro no lenho tardio (Figura $1 \mathrm{~A})$.

Vasos: pouco numerosos $(14,2 \pm 6,3(7,0$ $33,0)$ poros $\left./ \mathrm{mm}^{2}\right)$, em porosidade difusa, por 

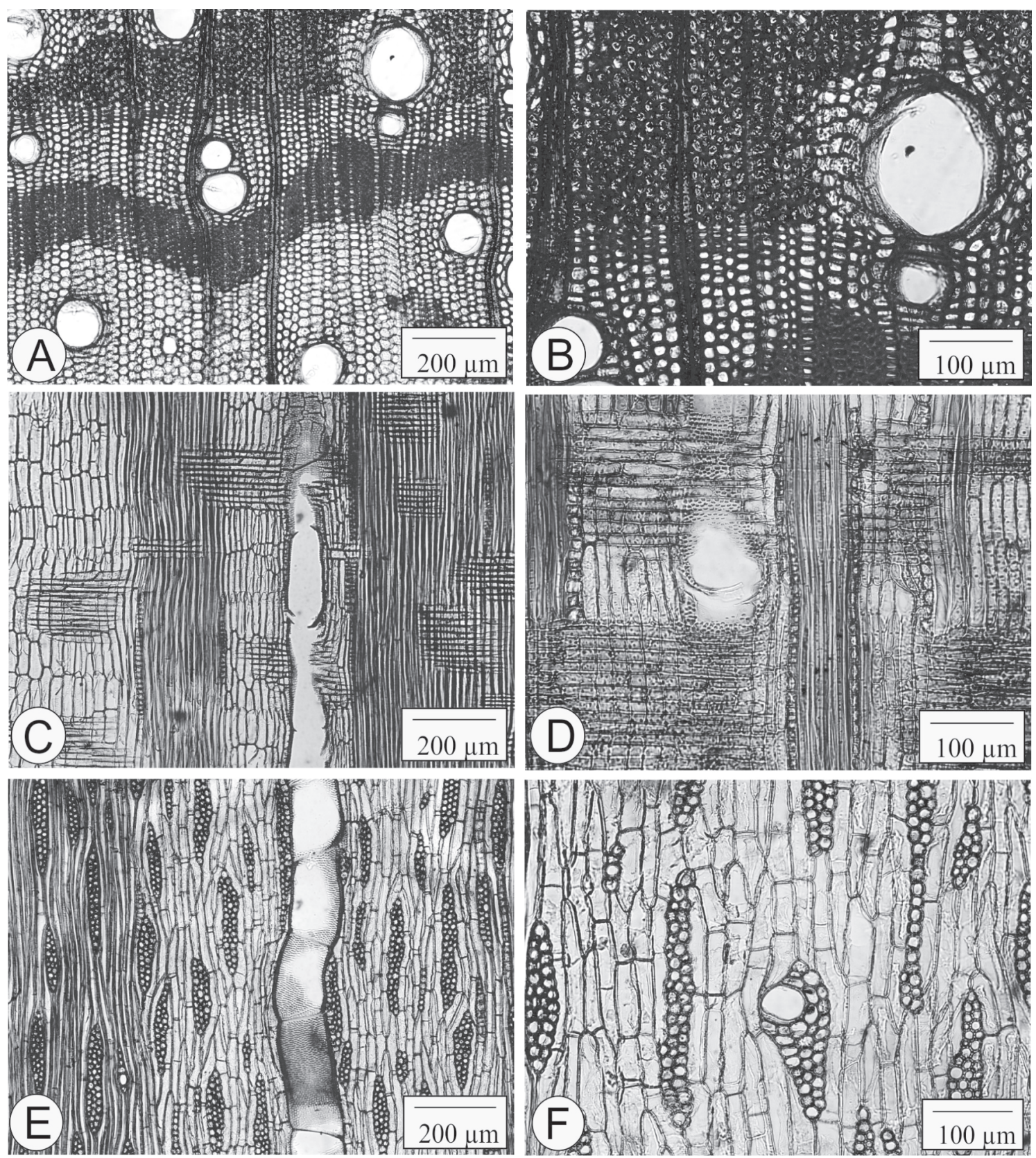

FIGURA 1 - Aspectos anatômicos da madeira de Albizia inundata. A - Anéis de crescimento distintos, demarcados por fibras radialmente achatadas, e porosidade difusa, uniforme (seção transversal). B - Parênquima paratraqueal-confluente e fibras gelatinosas (seção transversal). C - Raio homogêneo, composto inteiramente de células procumbentes (seção longitudinal radial). D - Cristais prismáticos na periferia das faixas de fibras, com 12 até mais de 20 câmaras (seção longitudinal radial). E - Raios multisseriados e unisseriados (seção longitudinal tangencial). F - Célula perfurada de raio e parênquima axial com 2 a 4 células por série (seção longitudinal tangencial). 
vezes em contato com raios. Poros arredonda$\operatorname{dos}(113,0 \pm 22,9(68,0-168,0) \mu \mathrm{m})$ e de paredes espessas $(7,0 \pm 2,0(3,0-10,0) \mu \mathrm{m})$, perfazendo $10 \%$ do volume da madeira. Poros solitários (72\%), menos comumente em múltiplos radiais de 2-5 (23\%), raramente em cachos de 3-6 unidades (5\%). Elementos vasculares curtos $(272 \pm 62,9(130-440) \mu \mathrm{m})$, com placas de perfuração simples, oblíquas a transversais, e apêndices curtos $(51 \pm 26,6(20-100) \mu \mathrm{m})$, em apenas uma extremidade. Tilos, espessamentos helicoidais, estriações e depósitos, ausentes. Pontoações intervasculares arredondadas $(7 \pm$ 1,1 (5-9) $\mu \mathrm{m}$ ), alternas, ornamentadas, com abertura lenticular, horizontal, inclusa. Pontoações raio-vasculares $(6 \pm 0,8(5-8) \mu \mathrm{m})$ e parênquimovasculares $(5 \pm 1,1(4-8) \mu \mathrm{m})$, semelhantes às intervasculares.

Parênquima axial: representando 39\% do volume da madeira; em arranjo paratraquealconfluente, compondo largas faixas, com mais de três células de largura (Figura 1A, B). Séries parenquimáticas de $358 \pm 68,6(220-580) \mu \mathrm{m}$ de altura, e $28 \pm 3,7$ (23-35) $\mu \mathrm{m}$ de largura, compostas por $2-4$ células (Figura 1E, F).

Raios: pouco numerosos ( $7 \pm 1,5$ (4-9) raios $/ \mathrm{mm}$ ), representando $20 \%$ do volume da madeira; homogêneos, compostos inteiramente de células procumbentes (Figura 1C, D). Tecido radial com contatos frequientes com vasos. Os unisseriados, escassos (12\%); de 108 $\pm 36,9$ (40200) $\mu \mathrm{m}$ de altura, com $6 \pm 2,3$ (3-11) células, e $19 \pm 6,2(13-35) \mu \mathrm{m}$ de largura. Os multisseriados (Figura 1E, F), inteiramente de células procumbentes, em sua maioria trisseriados $(45 \%)$, menos comumente bisseriados $(36 \%)$, raros tetrasseriados $(7 \%)$; de $245 \pm 35,1$ (170-340) $\mu \mathrm{m}$ de altura, com $18 \pm$ 4,5 (11-29) células, e $43 \pm 7,7$ (28-63) $\mu \mathrm{m}$ de largura. Raios fusionados, presentes. Células perfuradas, raras (Figura 1E). Raios agregados, células latericuliformes, células envolventes e células oleíferas, ausentes.

Fibras: libriformes, septadas, em faixas alternas com o parênquima axial (Figura 1A, B), compondo $31 \%$ do volume da madeira; curtas
$(915 \pm 134,7(690-1150) \mu \mathrm{m})$ e de paredes delgadas a espessas ( $3 \pm 0,6(2-4) \mu \mathrm{m})$. Pontoações simples, diminutas, verticais, nas faces radiais e tangenciais da parede. Fibras gelatinosas, em zonas dispersas no lenho (Figura 12A, B). Espessamentos helicoidais e traqueóides, ausentes.

Outros caracteres: cristais prismáticos, abundantes, em séries de 12 até mais de 20 câmaras, no parênquima adjacente às fibras. Máculas medulares, presentes. Canais celulares, cistos glandulares, estrutura estratificada, sílica, floema incluso, células oleíferas e células mucilaginosas, ausentes.

\section{ANÁLISE ANATÔMICA}

Os caracteres anatômicos observados no lenho de Albizia inundata concordam com relacionado por Record \& Hess (1943), para as Leguminosae, e por Metcalfe \& Chalk (1972), para as Mimosaceae e gênero Albizia Durazz.

Com relação às espécies sul-brasileiras de Albizia, o lenho em estudo assemelha-se mais ao de A. niopoides (Spruce ex Benth.) Burkart, devido às largas faixas de parênquima axial alternadas com faixas de fibras, bem como pela largura dos raios. Albizia inundata, todavia, separa-se, facilmente, de Albizia edwallii (Hoehne) Barneby \& J.W Grimes (= Albizia austrobrasilica Burkart), uma vez que esta espécie apresenta parênquima axial relativamente escasso, predominantemente vasicêntrico.

Por sua vez, o material em estudo coincide com as características qualitativas descritas por Tortorelli (1956) para Arthrosamanea polyantha, binômio atualmente reduzido à sinonímia de Albizia inundata, notadamente pelas largas faixas de parênquima axial alternadas com faixas de fibras, pelas fibras septadas, pelos poros predominantemente solitários, e pelos raios de até 4 células de largura. As pequenas diferenças observadas em caracteres quantitativos podem ser atribuídas à idade e/ou procedência do material examinado.

Espécie típica da mata ciliar, encontrada tanto junto à água como no alto dos taludes fluvi- 
TABELA 1 - Dados quantitativos do lenho de Albizia inundata

\begin{tabular}{|c|c|c|c|c|c|}
\hline Caracteres anatômicos & mín & $\mathbf{x}$ & máx & $\mathbf{S}$ & $\mathbf{C V}_{\%}$ \\
\hline Fração de vasos (\%) & 7,0 & 10,0 & 14,0 & 3,5 & 44,4 \\
\hline Frequência de vasos (vasos $\left./ \mathrm{mm}^{2}\right)$ & 7,0 & 14,2 & 33,0 & 6,3 & 12,1 \\
\hline$\varnothing$ total de vasos $(\mu \mathrm{m})$ & 98,0 & 122,0 & 150,0 & 14,8 & 20,3 \\
\hline$\varnothing$ do lúmen de vasos ( $\mu \mathrm{m})$ & 68,0 & 113,0 & 168,0 & 22,9 & 30,0 \\
\hline Espessura da parede de vasos ( $\mu \mathrm{m})$ & 3,0 & 7,0 & 10,0 & 2,1 & 23,1 \\
\hline Comprimento el. vasculares $(\mu \mathrm{m})$ & 130,0 & 272,0 & 440,0 & 62,9 & 52,1 \\
\hline Comprimento de apêndices ( $\mu \mathrm{m}$ ) & 20,0 & 51,0 & 100,0 & 26,6 & 15,7 \\
\hline O pontoações intervasculares ( $\mu \mathrm{m})$ & 5,0 & 7,0 & 9,0 & 1,1 & 16,0 \\
\hline Ø pontoações raio-vasculares $(\mu \mathrm{m})$ & 5,0 & 5,0 & 8,0 & 0,8 & 22,0 \\
\hline O pontoações parênq--vasculares ( $\mu \mathrm{m})$ & 4,0 & 5,0 & 8,0 & 1,1 & 31,0 \\
\hline Fração de raios $(\%)$ & 15,0 & 20,0 & 27,0 & 6,2 & 21,4 \\
\hline Frequência de raios (raios/mm) & 4,0 & 7,0 & 9,0 & 1,5 & 25,0 \\
\hline Fração de raios unisseriados $(\%)$ & 9,0 & 12,0 & 15,0 & 3,0 & 38,3 \\
\hline Altura raios unisseriados ( $n^{\circ}$ células) & 3,0 & 6,0 & 11,0 & 2,3 & 34,2 \\
\hline Altura raios unisseriados $(\mu \mathrm{m})$ & 40,0 & 108,0 & 200,0 & 36,9 & 32,6 \\
\hline Largura raios unissseriados $(\mu \mathrm{m})$ & 13,0 & 19,0 & 35,0 & 6,2 & 25,0 \\
\hline Altura raios multisseriados ( $n^{\circ}$ células) & 11,0 & 18,0 & 29,0 & 4,5 & 14,3 \\
\hline Altura raios multisseriados $(\mu \mathrm{m})$ & 170,0 & 245,0 & 340,0 & 35,0 & 17,9 \\
\hline Largura raios multisseriados $(\mu \mathrm{m})$ & 28,0 & 43,0 & 63,0 & 7,7 & 4,2 \\
\hline Fração raios bisseriados (\%) & 34,0 & 36,0 & 37,0 & 1,5 & 10,9 \\
\hline Fração raios trisseriados $(\%)$ & 39,0 & 45,0 & 48,0 & 4,9 & 75,7 \\
\hline Fração raios tetrasseriados $(\%)$ & 4,0 & 7,0 & 14,0 & 5,3 & 8,1 \\
\hline Fração de fibras $(\%)$ & 28,0 & 31,0 & 33,0 & 2,5 & 14,7 \\
\hline Comprimento de fibras ( $\mu \mathrm{m})$ & 690 & 915 & 1150 & 134 & 21 \\
\hline$\varnothing$ total de fibras $(\mu \mathrm{m})$ & 10 & 16 & 25 & 3,5 & 37 \\
\hline$\varnothing$ lúmen de fibras ( $\mu \mathrm{m})$ & 6 & 10 & 20 & 3 & 20 \\
\hline Espessura parede de fibras ( $\mu \mathrm{m})$ & 2 & 3 & 4 & 0,6 & 44 \\
\hline
\end{tabular}

Em que: mín = valor mínimo; $\mathrm{x}=$ média; Parênq. = parênquimo; máx = valor máximo; $\mathrm{s}=$ desvio padrão; $\mathrm{cv}_{\%}=\mathrm{coefici}$ ente de variação; el. = elementos; $\varnothing=$ diâmetro; $\mu \mathrm{m}=$ micrômetros.

ais, Albizia inundata não apresenta, todavia, o conjunto de caracteres descritos, por Denardi (2007), como típicos da "síndrome anatômica de reofilia", com exceção da abundância de parênquima axial e fibras gelatinosas, bem como pela parede relativamente delgada das fibras, em contraste com o descrito para Albizia niopoides e A. edwallii, espécies sabidamente não reófilas.

\section{REFERÊNCIAS BIBLIOGRÁFICAS}

BRUSSA SANTANDER, C.A.; GRELA GONZÁLEZ, I.A. Flora arbórea del Uruguay. Montevideo: COFUSA, 2007. 542 p.
BURGER, L.M.; RICHTER, H.G. Anatomia da Madeira. São Paulo: Nobel, 1991. 154 p.

BURKART, A. Leguminosas Mimosóideas. In: REITZ, P.R. Flora Ilustrada Catarinense. Itajaí: Herbário Barbosa Rodrigues, 1979. 299 p.

BURKART, A. Leguminosae (= Fabaceae), Leguminosas. In: BURKART, A.; BURKART, N.S.T de; BACIGALUPO, N.M. Flora Ilustrada de Entre Rios (Argentina). Buenos Aires: Colección Científica del INTA, 1987. p. 442-738.

DENARDI, L. Anatomia e flexibilidade do caule de quatro espécies lenhosas para o manejo biotécnico de cursos de água. $112 \mathrm{f}$. Tese (Doutorado em Eng. Florestal) - Universidade Federal de Santa Maria. Santa Maria, 2007. 
IAWA COMMITTEE. IAWA list of microscopic features for hardwood identification. IAWA Bulletin, v. 10, n. 3, p. 218-359, 1989.

IZAGUIRRE, P.; BEYHAUT, R. Las Leguminosas en Uruguay y regiones vecinas. Montevideo: Hemisfério Sur, 2003. 301 p.

LORENZI, H. Árvores brasileiras. Manual de identificação e cultivo de plantas arbóreas do Brasil. Nova Odessa: Instituto Plantarum, 1998. v. $2.352 \mathrm{p}$.

MARCHIORI, J.N.C. Comprovação da viabilidade da utilização da seção longitudinal tangencial para a determinação histométrica dos elementos axiais do xilema secundário. In: Anais. Nova Prata, RS: IV Congresso Florestal Estadual,1980. p. 180-184.

MARCHIORI, J.N.C. Anatomia da madeira do angico-branco, Albizia austrobrasilica Burk. Ciência e Natura, Santa Maria, n. 17, p. 75-86. 1995.

MARCHIORI, J.N.C. Dendrologia das Angiospermas: Leguminosas. Santa Maria: Ed. UFSM, 1997. $200 \mathrm{p}$.

MARCHIORI, J.N.C. Dendrologia das Angiospermas: Leguminosas. Santa Maria: Ed. da UFSM, 2007. $2^{\text {a }}$ ed. 199 p.
MARCHIORI, J.N.C.; ALVES, F. da S. Nota sobre a ocorrência natural de Albizia inundata (Mart.) Barneby \& Grimes no Rio Grande do Sul. Balduinia, Santa Maria, n. 33, p. 21-25, 2012.

MARCHIORI, J.N.C.; MUÑIZ, G.I.B. de; SANTOS, S.R. dos. Madeiras do Rio Grande do Sul. 1 Descrição microscópica de 33 espécies nativas. Santa Maria: [s.n.], 2009. 80 p.

MATTOS, P.P. de; TEIXEIRA, L.L.; SEITZ, R.A.; SALIS, S.M. de; BOTOSSO, P.C. Anatomia de madeiras do Pantanal Mato-Grossense. Colombo: Embrapa Florestas; Corumbá: Embrapa Pantanal, 2003. 182 p.

METCALFE, C.R.; CHALK, L. Anatomy of the Dicotyledons. Oxford: Clarendon Press, 1972. v. $1.724 \mathrm{p}$.

RECORD, S.J.; HESS, R.W. Timbers of the New World. New Haven: Yale University Press, 1943. $640 \mathrm{p}$.

SOBRAL, M.; JARENKOW, J.A.; BRACK, P.; IRGANG, B.; LAROCCA, J.; RODRIGUES, R.S. Flora arbórea e arborescente do Rio Grande do Sul, Brasil. São Carlos: RiMA : Novo Ambiente, 2006. 350 p.

TORTORELLI, L.A. Maderas y bosques argentinos. Buenos Aires: ACME, 1956. 910 p. 